\title{
Faktor yang Mempengaruhi Kelengkapan Imunisasi Dasar pada Bayi di Wilayah Kerja Puskesmas Peukan Bada Kabupaten Aceh Besar
}

\author{
Factors That Influence The Completeness of Basic Immunization in Babies in \\ The Working Areas of Bada's Health Center Aceh Besar District
}

\author{
Nuzulul Rahmi * ${ }^{*}$, Asmaul Husna ${ }^{2}$ \\ ${ }^{1}$ Prodi Diploma III Kebidanan, Universitas Ubudiyah Indonesia, Jalan Alue Naga, Desa \\ Tibang, Kota Banda Aceh, Indonesia \\ ${ }^{2}$ Prodi Diploma IV Kebidanan, Universitas Ubudiyah Indonesia, Jalan Alue Naga, Desa \\ Tibang, Kota Banda Aceh, Indonesia
}

*Korespodensi Penulis: nuzulul_r@uui.ac.id

\begin{abstract}
Abstrak
Cakupan imunisasi dasar lengkap (IDL) di Indonesia pada 2016 sebesar 91,58 persen dan Provinsi Aceh menduduki peringkat empat terbawah dari seluruh provinsi yaitu 69,11 persen. Pada tahun 2017 IDL di Indonesia turun yaitu 90,8 persen dan Provinsi Aceh menduduki peringkat tiga terbawah yaitu 70 persen (Kemenkes RI, 2016 dan 2017). Banyak faktor yang menyebabkan ketidakberhasilan program imunisasi dasar lengkap.Penelitian ini adalah survey dengan desain kasus control dengan perbandingan sampel 1:1 yaitu 40 kasus dan 40 kontrol. Instrumen penelitian menggunakan kuesioner yang dibagikan dari tanggal 05 Juni s/d 07 Agustus 2018. Hasil analisis data bivariat didapatkan bahwa ada pengaruh antara sikap petugas kesehatan ( $\mathrm{p}$ value $0,001, \mathrm{OR} 9,471$ ) dan dukungan keluarga ( $\mathrm{p}$ value 0,001 , OR 16,333) dengan kelengkapan imunisasi dasar pada bayi di wilayah kerja Puskesmas Peukan Bada Tahun 2018. Tidak ada pengaruh antara pengetahuan ( $\mathrm{p}$ value 0,502, OR 0,669), jumlah anak ( $\mathrm{p}$ value 0,156, OR 2,217) dan jarak rumah ( $\mathrm{p}$ value 0,50 , OR 1,50) dengan kelengkapan imunisasi dasar pada bayi di wilayah kerja Puskesmas Peukan Bada. Berdasarkan hasil analisis data multivariat, varibel yang paling dominan berpengaruh terhadap kelengkapan imunisasi dasar pada bayi adalah dukungan kelurga (OR 12,73).
\end{abstract}

Kata Kunci : Imunisasi, imunisasi lengkap, status imunisasi

\begin{abstract}
Complete basic immunization coverage (IDL) in Indonesia in 2016 amounted to 91.58 percent and Aceh Province was ranked as the fourth lowest of all provinces, namely 69.11 percent. In 2017 IDL in Indonesia dropped by 90.8 percent and Aceh Province was ranked as the third lowest at 70 percent (Indonesian Ministry of Health, 2016 and 2017). Many factors cause the failure of a complete basic immunization program. This study is a case control survey with a 1: 1 sample ratio of 40 cases and 40 controls. The research instrument used a questionnaire distributed from June 5 to August 7 2018. The results of bivariate data analysis showed that there was an influence between attitudes of health workers ( $p$ value 0.001, OR 9,471) and family support ( $p$ value 0.001, OR 16,333) with completeness basic immunization for infants in the Peukan Bada Community Health Center working area in 2018. There is no influence between knowledge ( $p$ value 0.502, OR 0.669), number of children ( $p$ value 0.156, OR 2.217) and distance of home ( $p$ value 0.50, OR 1, 50) with complete basic immunization for
\end{abstract}


infants in the Peukan Bada Puskesmas working area. Based on the results of multivariate data analysis, the most dominant variable influencing the completeness of basic immunization in infants was family support (OR 12.73).

Keywords : Immunization, complete immunization, immunization status

\section{PENDAHULUAN}

Imunisasi merupakan usaha memberikan kekebalan pada bayi dan anak dengan memasukkan vaksin kedalam tubuh agar tubuh membuat zat anti untuk mencegah terhadap penyakit tertentu. Sedangkan yang dimaksud vaksin adalah bahan yang dipakai untuk merangsang pembentukan zat anti yang dimasukkan kedalam tubuh melalui suntikan seperti vaksin BCG, DPT, Campak, dan melalui mulut seperti vaksin polio. Tujuan diberikan imunisasi adalah diharapkan anak menjadi kebal terhadap penyakit sehingga dapat menurunkan angka morbiditas dan mortalitas serta dapat mengurangi kecacatan akibat penyakit tertentu (Aziz, 2009).

Cakupan imunisasi dasar lengkap (IDL) di Indonesia pada 2016 sebesar 91,58 persen dan Provinsi Aceh menduduki peringkat empat terbawah dari seluruh provinsi yaitu 69,11 persen. Pada tahun 2017 IDL di Indonesia turun yaitu 90,8 persen dan Provinsi Aceh menduduki peringkat tiga terbawah yaitu 70 persen (Kemenkes RI, 2016 dan 2017).

Kecamatan Peukan Bada terdiri dari 18 desa, yaitu : Lampageu, lambaro Neujib, Lambadeuk, Lamguron, Lamteongoh, Lamtutui, Meunasah Tuha, Lam awe, Lammanyang, KP. Baro, Lamteh, Lam Isek, Gurah, Lamrukam, Lamkeumok, Lamlumpu, Lamgeu-eu, dan Pulo Bunta. Data Puskesmas Peukan Bada sampai dengan bulan Mei 2018 ada 7 desa yang belum mencapai cakupan Desa Universal Child Immunization (UCI). Hal ini dilihat dari imunisasi perdesanya, dimana ada 7 desa yang cakupan kelengkapan imunisasinya masih dibawah 100\%, yaitu : Lambaro Neujib 70\%, Meunasah Tuha 85\%, Lam Awe 65\%, Lam Manyang 75\%, Lam Isek 84\%, Gurah 50\%, dan Lamlumpui 40\%. (Laporan Puskesmas Peukan Bada). Maka dari itu peneliti tertarik untuk meneliti faktor apa yang mempengaruhi kelengkapan imunisasi dasar pada bayi di wilayah kerja Puskesmas Peukan Bada Kabupaten Aceh Besar. 


\section{METODE PENELITIAN}

Jenis penelitian ini adalah penelitian survey yang bersifat deskriptif analitik dengan desain Kasus Kontrol. Penelitian ini dilakukan di wilayah kerja Puskesmas Peukan Bada dari tanggal 05 Juni s/d 07 Agustus 2018. Sampel dalam penelitian ini dengan teknik purposive sampling, yang ditetapkan dalam penelitian ini adalah sampel kasus 40 responden dan sampel kontrol 40 responden. Data dianalisis secara statistik menggunakan aplikasi komputer. Analisis Chi Square digunakan untuk mengetahui hubungan pengetahuan, jumlah anak, sikap petugas kesehatan, dukungan keluarga dan jarak rumah dengan kelengkapan imunisasi dasar dan ditentukan pula variable manakah yang paling dominan mempengaruhi kelengkapan imunisasi. Nilai yang dilihat untuk mengetahui kedua variabel ada hubungan adalah dengan $p$ value $<0.05$

\section{HASIL DAN PEMBAHASAN}

1. Analisis Univariat

Tabel 1. Distribusi Frekuensi Faktor Yang Mempengaruhi Kelengkapan Imunisasi Dasar Pada Bayi Di Wilayah Kerja Puskesmas Peukan Bada Tahun 2018

\begin{tabular}{|c|c|c|c|}
\hline No & Variabel & Frekuensi (f) & Persentase $(\%)$ \\
\hline \multirow[t]{3}{*}{1} & Status Imunisasi & & \\
\hline & a. Lengkap (Kasus) & 40 & 50 \\
\hline & b. Tidak lengkap (Kontrol) & 40 & 50 \\
\hline \multirow[t]{3}{*}{2} & Pengetahuan Ibu & & \\
\hline & a. Tinggi & 40 & 50 \\
\hline & b. Rendah & 40 & 50 \\
\hline \multirow[t]{3}{*}{3} & Jumlah Anak & & \\
\hline & a. $\leq 2$ & 53 & 66.2 \\
\hline & b. $>2$ & 27 & 33.8 \\
\hline \multirow[t]{3}{*}{4} & Sikap Petugas Kesehatan & & \\
\hline & a. Baik & 28 & 35 \\
\hline & b. Buruk & 52 & 65 \\
\hline \multirow[t]{3}{*}{5} & Dukungan Keluarga & & \\
\hline & a. Ada & 47 & 58.8 \\
\hline & b. Tidak Ada & 33 & 41.2 \\
\hline \multirow[t]{3}{*}{6} & Jarak Rumah & & \\
\hline & a. Dekat & 36 & 45 \\
\hline & b. Jauh & 44 & 55 \\
\hline Total & & 80 & 100 \\
\hline
\end{tabular}

Berdasarkan tabel 4.1 terlihat bahwa Status Imunisasi dengan sampel kontrol (status imunisasi lengkap) 50\% dan sampel kasus (ststus imunisasi tidak lengkap) 50\%. Pengetahuan 
Ibu 50\% berpengetahuan tinggi, jumlah anak kurang dari samadengan 2 sebesar 66,2 \%, sikap petugas kesehatan lebih banyak katagori yang buruk yaitu $65 \%$. Keluarga yang mendukung terhadap imunisasi sebesar 58,8 \% dan jarak rumah ke tempat pelayanan imunisasi yang berjarak pada katagori jauh sebesar $55 \%$.

2. Analisis Bivariat

Tabel 2. Faktor Yang Mempengaruhi Kelengkapan Imunisasi Dasar Pada Bayi Di Wilayah Kerja Puskesmas Peukan Bada Tahun 2018

\begin{tabular}{|c|c|c|c|c|c|c|c|c|}
\hline \multirow[b]{2}{*}{ No } & \multirow{2}{*}{$\begin{array}{c}\text { Variabel } \\
\text { Independen }\end{array}$} & \multirow[b]{2}{*}{ Katagori } & \multicolumn{4}{|c|}{ Status Imunisasi } & \multirow{2}{*}{$\begin{array}{c}P \\
\text { Value }\end{array}$} & \multirow[b]{2}{*}{ OR } \\
\hline & & & Lengkap & $\mathrm{f}$ & $\begin{array}{c}\text { Tidak } \\
\text { Lengkap }\end{array}$ & $f$ & & \\
\hline \multirow[b]{2}{*}{1.} & \multirow[b]{2}{*}{ Pengetahuan } & Tinggi & 18 & 45 & 22 & 55 & \multirow[b]{2}{*}{0,502} & \multirow[b]{2}{*}{0,669} \\
\hline & & Rendah & 22 & 55 & 18 & 45 & & \\
\hline \multirow{2}{*}{2.} & \multirow{2}{*}{ Jumlah anak } & $\leq 2$ & 30 & 75 & 23 & 57,5 & \multirow{2}{*}{0,156} & \multirow{2}{*}{2,217} \\
\hline & & $\geq 2$ & 10 & 25 & 17 & 42,5 & & \\
\hline \multirow{2}{*}{3.} & \multirow{2}{*}{$\begin{array}{l}\text { Sikap } \\
\text { petugas } \\
\text { kesehatan }\end{array}$} & Baik & 23 & 57,5 & 5 & 12,5 & \multirow{2}{*}{0,001} & \multirow{2}{*}{9,471} \\
\hline & & Buruk & 17 & 42,5 & 35 & 87,5 & & \\
\hline \multirow{2}{*}{4.} & \multirow{2}{*}{$\begin{array}{l}\text { Dukungan } \\
\text { keluaraga }\end{array}$} & Ada & 35 & 87,5 & 12 & 30 & \multirow{2}{*}{0.001} & \multirow{2}{*}{16,33} \\
\hline & & Tidak ada & 5 & 12,5 & 28 & 70 & & \\
\hline \multirow{2}{*}{5.} & \multirow{2}{*}{ Jarak rumah } & Dekat & 20 & 50 & 16 & 40 & \multirow{2}{*}{0,50} & \multirow{2}{*}{1,500} \\
\hline & & Jauh & 20 & 50 & 24 & 60 & & \\
\hline
\end{tabular}

3. Analisis Multivariat

Hasil seleksi bivariat terdapat bahwa 3 variabel independen memiliki $p$ value $<0,25$ dan 2 variabel independen memiliki $p$ value $>0,25$, dengan demikian variabel umur, pendidikan dan pekerjaan tidak dilanjutkan ke analisis multivariat, selanjutnya keenam variabel tersemut dimasukkan kedalam model dengan hasil sebagai berikut : 
Tabel 3. Pemodelan Multivariat Pertama

\begin{tabular}{clccc}
\hline No & & Variabel & p value & OR \\
\hline 1 & Jumlah Anak & 0.926 & 0.93 \\
2 & Sikap & 0.006 & 6.60 \\
3 & Dukungan Keluarga & 0.001 & 13.19 \\
\hline
\end{tabular}

Hasil pemodelan pertama multivariate ternyata ada 1 variabel yang $p$ value $>0,05$ yaitu variabel jumlah anak, langkah selanjutnya variabel jumlah anak dikeluarkan dari pemodelan dan hasilnya sebagai berikut :

Tabel 4. Pemodelan Multivariat Kedua

\begin{tabular}{llccc}
\hline No & \multicolumn{1}{c}{ Variabel } & p value & $\begin{array}{c}\text { OR lama dan OR } \\
\text { Baru }\end{array}$ & Perubahan (\%) \\
\hline 1 & Sikap Petugas & 0.004 & $6.60-6.71$ & 1.7 \\
2 & Dukungan Keluarga & 0.001 & $13.19-12.73$ & 3.5 \\
\hline
\end{tabular}

Hasil pemodelan analisis multivariate kedua didapatkan perubahan nilai OR tidak ada yang lebih dari $10 \%$ dan ada 2 variabel yang berhubungan dengan nilai $\mathrm{p}$ value dan OR sebagai berikut :

Tabel 5. Pemodelan Multivariat Terakhir

\begin{tabular}{clccc}
\hline No & & Variabel & p value & OR \\
\hline 1 & Sikap Petugas & 0.004 & 6.71 \\
2 & Dukungan Keluarga & 0.001 & 12.73 \\
\hline
\end{tabular}

Hasil pemodelan analisi multivariate terakhir ada 2 variabel yang berhubungan dengan kelengkapan imunisasi dasar lengkap yaitu sikap petugas dan dukungan keluarga. Dari dua variabel tersebut, variabel yang dominan berhubungan dengan kelengkapan imunisasi dasar adalah dukungan keluarga dengan nilai OR 12,73, artinya keluarga yang mendukung program imunisai 12 kali lebih lengkap status imunisasi dasar anaknya dibandingkan dengan keluarga yang tidak mendukung program imunisasi. Dukungan dari keluarga terutama yang serumah dengan Ibu menjadi kekuatan emosional tersendiri bagi ibu ibu untuk mengimunisasi anaknya secara lengkap. Keluarga tidak hanya menemani saat imunisasi tetapi juga merawat bayi yang demam dan rewel akibat imunisasi. Ibu menjadi tidak khawatir dan tidak disalakahkan apabila anak demam dan rewel setelah imunisasi. 


\section{Pembahasan}

a. Pengaruh Pengetahuan terhadap Kelengkapan Imunisasi Dasar

Berdasarkan hasil penelitian yang telah dilakukan oleh peneliti Ibu dengan pengetahuan rendah ada $55 \%$ dengan status imunisasi lengkap dan $45 \%$ dengan status imunisasi tidak lengkap. Hasil analisis bivariat didapatkan nilai p 0,502 yang artinya tidak ada pengaruh antara pengetahuan Ibu tentang imunisasi terhadap kelengkapan status imunisasi pada bayi.

Hasil penelitian ini sama dengan hasil penelitian Prayogo dkk di tahun 2009 tentang kelengkapan imunisasi dasar pada anak usia 1-5 tahun di RW 04 kelurahan Jati Jakarta Timur yaitu tidak ada hubungan bermakna antara pengetahuan dengan kelengkapan imunisasi dasar pada anak. Namun kecenderungan yang terlihat anak kelompok responden dengan tingkat pengetahuan yang kurang memiliki kemungkinan lebih besar mengalami ketidaklengkapan imunisasi dasar.

Hasil penelitian lainnya yang sama dengan penelitian ini adalah penelitian Afriani dkk (2014) dengan judul faktor-faktor yang berhubungan dengan kelengkapan imunisasi dasar pada anak dan pengelolaan vaksin di Puskesmas dan Posyandu Kecamatan X Kota Depok dengan hasil tidak ada hubungan bermakna antara pengetahuan dan kelengkapan imunisasi dasar anak. Hsil penelitian menunjukkan hamper 100\% ibu mengetahui tentang program imunisasi dan tujuan imunisasi dan informasi penting tentang imunisasi telah disebar luaskan oleh petugas kesehatan kepada masyarakat. Untuk menialai hubungan anatar pengetahuan ibu dan kelengkapan imunisasi dasar pada anak akan lebih baik jika pertanyaan mengacu pada pengertian, tujua, manfaat, jenis dan jadwal imunisasi sehingga dapat terlihat apakah ibu mnengetahui kapan dan berapa kali anak harus mendapat imunisisasi.

Hasil penelitian ini tidak sesuai dengan penelitian yang dilakukan oleh Dewi, dkk (2013) tentang hubungan tingkat pengetahuan ibu dengan pemberian imunisasi dasar lengkap pada bayi di kelurahan Parapuk Tabing wilayah kerja puskesmas Lunbuk Buaya Kota Padang dengan taraf signifikan 0,000 yang bermakna ada hubungan antara pengetahuan dengan pemberian imunisasi dasar. Beberapa pertanyaan dalam kuesioner tentang pengetahuan imunisasi dasar lengkap ditemukan kurang dari 60\% ibu yang menjawab dengan benar. Penyebabnya adalah ibu-ibu kurang terpapar dengan materi yang di tanyakan, sehingga ibu tidak dapat menjawab dengan benar. Hal ini dapat dicegah 
dengan kegiatan penyuluhan tentang imunisasi dasar lengkap kepada ibu. Penyuluhan tersebut harus mencakupi semua hal yang berhubungan tentang imunisasi terutama tentang jadwal pemberian, frekuensi pemberian dan fungsi dari masing-masing imunisasi tersebut.Sehingga dapat meningkatkan pemahaman ibu tentang imunisasi dasar lengkap.

Hasil penelitian ini juga tidak sesuai dengan teori dari Notoatmodjo (2014) yaitu ada pengaruh pengetahuan ibu Terhadap kelengkapan imunisasi Dasar Bayi sesuai dengan teori yang dinyatakan bahwa seseorang melakukan tindakan dengan didasarkan oleh suatu pengetahuan. Hal ini disebabkan karena pengetahuan merupakan domain yang sangat penting untuk terbentuknya tindakan seseorang.

Menurut peneliti, pengetahuan ibu tidak mempunyai pengaruh yang bermakna terhadap kelengkapan imunisasi dasar pada bayi karena ibu dengan pengetahuan rendah tetap mengimunisasi bayinya dan status imunisasi bayinya lengkap hal ini disebabkan karena faktor lainnya seperti dukungan keluarga, informasi dari petugas, informasi dari media sehingga ibu ibu hanya mengetahui bahwa imunisasi itu penting bagi bayinya sehingga ibu dengan pengetahuan rendah tentang imunisasi tetap mengimunisasi bayinya secara lengkap. Adapula ibu dengan pengetahuan tinggi yang tidak mengimunisasi bayinya secara lengkap karena tidak mau bayinya menjadi demam, takut akan vaksin palsu dan tidak diizinkan oleh suami.

\section{b. Pengaruh Jumlah Anak terhadap Kelengkapan Imunisasi Dasar}

Berdasarkan hasil penelitian yang telah dilakukan oleh peneliti Ibu dengan jumlah anak $\geq 2$ ada $25 \%$ dengan status imunisasi yang lengkap dan 42,5\% dengan status imunisasi yang tidak lengkap. Hasil analisis bivariat didapatkan nilai p 0,156 yang artinya tidak ada pengaruh antara jumlah anak dengan kelengkapan status imunisasi pada bayi.

Hasil penelitian ini sama dengan penelitian Rini (2010) tentang hubungan antara karateristik, jumlah anak dan pengetahuan ibu terhadap status kelengkapan imunisasi dasar pada bayi di kelurahan Wonokusumo Kecamatan Semampir Surabaya. Berdasarkan hasil penelitiannya disimpulkan bahwa tidak ada hubungan jumlah anak dengan kelengkapan status imunisasi bayi, hal lainnya seperti karakteristik Ibu terutama pendidikan dan pengetahuan ibu mempunyai peranan dalam meningkatkan cakupan imunisasi. 
Hasil penelitian Pamungkas (2016) dengan judul hubungan jumlah anak dalam keluarga dengan kelengkapan imunisasi dasar anak di desa Sukowiryo Kecamatan Jelbuk kabupaten Jember dengan hasil p value 1,00 yaitu tidak ada hubungan antara jumlah anak dengan kelengkapan status imunisasi pada anak. Hal ini dikarenakan sebagian besar ibu telah melengkapi imunisasi anaknya dan telah merencanakan jumlah anak yang dimiliki sehingga mempengaruhi korelasi antara jumlah anak dalam keluarga dengan kelengkapan imunisasi dasar anak.

Hasil penelitian berbeda dikemukakan oleh Prayogo dkk di tahun 2009 tentang kelengkapan imunisasi dasar pada anak usia 1-5 tahun di RW 04 kelurahan Jati Jakarta Timur menunjukkan hal yang berbeda yaitu ada hubungan antara jumlah anak dengan kelengkapan imunisasi. Kelengkapan imunisasi dasar anak pertama lebih baik jika dibandingkan dengan kelengkapan imunisasi dasar anak bukan urutan pertama, berarti semakin banyak jumlah anak dalam keluarga akan menyebabkan imunisasi dasar anak tidak lengkap.

Menurut peneliti walaupun tidak ada pengaruh antara jumlah anak terhadap status imunisasi namun dapat disimpulkan bahwa ibu yang memiliki anak lebih dari 2 orang lebih banyak tidak mengimunisasi anaknya dengan lengkap sedangkan ibu yang memiliki jumlah anak kurang dari 2 mengimunisasi anaknya lebih lengkap. Namun tidak semua ibu yang memiliki anak lebih dari 2 tidak melakukan imunisasi anak hingga lengkap disebebkan ibu ibu tersebut menginginkan anaknya terlindung dari penyakit yang berbahaya. Adapula ibu yang hanya memiliki 1 atau 2 orang anak malah tidak mengimunisasi anaknya disebabkan oleh ibu takut apabila anaknya demam, takut akan vaksin palsu dan kandungan zat yang haram terdapat dalam vaksin.

\section{c. Pengaruh Sikap petugas terhadap kelengkapan imunisasi dasar}

Berdasarkan hasil penelitian yang telah dilakukan oleh peneliti didapatkan bahwa Ibu yang menilai sikap petugas yang buruk dalam meberikan pelayanan imunisasi ada $42,5 \%$ dengan ststus imunisasi yang lengkap dan 87,5 \% dengan status imunisasi yang tidak lengkap. Hasil analisis bivariat didapatkan nilai p 0,001 yang artinya ada pengaruh sikap petugas kesehatan terhadap kelengkapan status imunisasi dasar pada bayi.

Hasil penelitian ini sama dengan penelitian yang dilakukan oleh Ismet (2013) dengan judul Analisis Faktor-Faktor yang Berhubungan dengan Imunisasi Dasar Lengkap Pada 
Balita di Desa Botubarani Kecamatan Kabila Bone Kabupaten Bone Bolango didapatkan hasil $\mathrm{p}$ value 0,00 yang artinya ada hubungan sikap/pelayanan petugas kesehatan terhadap kelengkapan imunisasi dasar bayi. Pelayanan yang baik dari petugas kesehatan sangat mempengaruhi status imunisasi dasar lengkap pada balita. Petugas yang bersikap ramah, baik dan selalu memberikan informasi tentang pentingnya imunisasi dasar pada balita akan mempengaruhi ibu-ibu yang mempunyai balita akan datang ke tempat pelayanan kesehatan dalam hal ini Posyandu untuk mengimunisasikan anaknya dengan lengkap.

Hasil penelitian lainnya diungkapkan oleh Rahmawati dan Umbul (2014) dengan judul faktor yang mempengaruhi kelengkapan imunisasi dasar di kelurahan Krembangan Utara dengan hasil $\mathrm{p}$ value 1,00. Berdasarkan analisis pengaruh antara sikap petugas dengan kelengkapan imunisasi tidak ada pengaruh antara sikap petugas terhadap kelengkapan status imunisasi pada bayi atau balita. Tidak adanya pengaruh ini disebabkan karena dari hasil penelitian diketahui sebagian besar responden menyatakan bahwa petugas bersikap ramah terhadap responden.Sehingga tidak ada penghalang responden berkaitan dengan sikap petugas untuk memberikan imunisasi bagi bayi atau balitanya, dan dengan adanya sikap petugas yang ramah menyebabkan responden khususnya para ibu semangat untuk mengantarkan anaknya ke posyandu untuk diberikan imunisasi atau hanya sekedar melakukan penimbangan.

Menurut Suparmanto (2011) bahwa petugas kesehatan bertanggung jawab untuk memberikan pelayanan kesehatan dengan menunjukkan sikap yang professional dalam melakukan pelayanan imunisasi bagi individu dan keluarga, dengan ini diharapkan ibu mau mengimunisasi bayinya berkat penjelasan dan sikap petugas kesehatan.

Menurut peneliti sikap petugas kesehatan dalam meberikan pelayanan imunisasi berkontribusi untuk kelengkapan imunisasi dasar pada anak. Sikap petugas yang ramah dan professional akan memberikan dampak yang positif bagi keluarga sehingga keluarga termotivasi untuk mengimunisasi bayinya dengan lengkap. Apabila petugas kesehatan secara ramah dan profeional dalam memberikan informasi tentang tujuan, manfaat dan jadwal imunisasi secara jelas dan terus menerus kepada keluarga hal ini akan meningkatkan motivasi dan keinginan keluarga untuk mengimunisasi anaknya secara lengkap dan akan meningkatkan angka imunisasi lengkap pada anak. Maka sangat diharapkan peran serta petugas kesehatan untuk dapat bersikap ramah dan professional dalam memberikan pelayanan imunisasi. 
Jika ada keluarga yang tidak membawa anaknya untuk imunisasi ke Puskesmas atau Posyandu, maka petugas kesehatanlah yang mengunjungi rumah anak tersebut untuk memberikan koseling tentang pentingnya imunisasi pada anak dan melakukan imunisasi sehingga peran serta petugas dalam imunisasi sangat optimal. Di lapangan juga dijumpai petugas kesehatan telah bersikap ramah dan professional tetapi keluarga tetap tidak mengimunisasi anaknya secara lengkap, hal ini disebabakan oleh tidak adanya dukungan dari suami, atau bahkan dilarang oleh suami, ada pengalaman anak demam dan step setelah imunisasi dan adanya isu yang berkembang di masyarakat bahwa vaksin imunisasi mengandung zat yang haram bagi umat Islam.

d. Pengaruh Dukungan keluarga terhadap kelangkapan imunisasi dasar

Hasil penelitian yang didapatkan bahwa Ibu yang tidak mendapatkan dukungan dari keluarga untuk imunisasi ada 12,5\% dengan ststus imunisasi yang lengkap dan $70 \%$ dengan status imunisasi yang tidak lengkap. Hasil analisis bivariat didapatkan nilai p 0,001 yang artinya ada pengaruh dukungan keluarga untuk imunisasi dengan kelengkapan status imunisasi pada bayi.

Penelitian yang sama dilakukan oleh Rahmawati dan Umbul (2014) dengan judul faktor yang mempengaruhi kelengkapan imunisasi dasar di kelurahan Krembangan Utara dengan hasil $\mathrm{p}$ value 0,001 yang bermakna ada hubungan dukungan keluarga dengan kelengkapan imunisasi dasar. Terdapat adanya pengaruh ini dikarenakan responden yang memilki bayi atau balita dengan status imunisasi tidak lengkap sebagian besar tidak mendapat dukungan dari keluarganya, dan hal itu bertolak belakang dengan responden yang memilki bayi atau balita dengan status imunisasi lengkap yang sebagian besar mendapat dukungan dari keluarga, namun ada pula keluarga didalamnya tidak mendukung tetapi pengetahuan ibu tergolong baik sehingga ibu dapat memberikan pelayanan kesehatan bagi bayi atau balitanya. Dan dukungan keluarga juga berkaitan dengan tradisi, apabila tradisi dikeluarga terbiasa memberikan imunisasi maka secara otomatis keluarga yang ada didalamnya juga mendukung untuk pemberian imunisasi.

Penelitian dengan hasil yang sama dilakukan oleh Utami, dkk (2015) dengan judul hubungan dukungan keluarga dengan motivasi ibu dalam mendapatkan imunisasi dasar lengkap pada bayi usia 0-12 bulan di desa Nyabakan Barat dengan hasil p value 0,000 yang artinya ada hubungan dukungan keluarga motivasi ibu dalam mendapatkan imunisasi dasar 
lengkap. Dukungan keluarga yang baik dan motivasi yang kuat dapat mempengaruhi capaian imunisasi dasar lengkap.

Penelitian yang berbeda didaptkan oleh Ilham (2017) dengan judul Hubungan dukungan keluarga dengan kepatuhan ibu melaksanakan imunisasi dasar lengkap pada bayi di wilayah kerja puskesmas Pemangkat Kabupaten Sambas dengan hasil tidak ada hubungan dukungan keluarga dengan kepatuhan ibu melakukan imunisasi lengkap pada bayi. Informasi dapat mengarahkan individu yang khususnya seorang Ibu ataupun anggota keluarga lainnya agar munculnya dukungan kelaurga terhadap ibu untuk melaksanakan imunisasi dasar lengkap dan membentuk opini kelauarga maupun ibu yang baik terhadap kelengkapan imunisasi.

Menurut teori Suparmanto (2011) bahwa lingkungan kebudayaan dimana orang banyak belajar dari lingkungan kebudayaan sekitarnya. Pengaruh keluarga bagi pembentukan sikap sikap amatlah besar karena keluarga merupakan orang yang paling dekat dengan anggota keluarga yang lain. Jika anggota keluarga lainnya kurang begitu perduli atau tidak merespon positif terhadap pemberian imunisasi maka pelaksanaan imunisasi tidak akan dilakukan oleh ibu bayi karena kurangnya dukungan dari keluarga.

Menurut peneliti dukungan dari keluarga terutama yang serumah dengan Ibu menjadi kekuatan emosional tersendiri bagi ibu ibu untuk mengimunisasi anaknya secara lengkap. Keluarga tidak hanya menemani saat imunisasi tetapi juga merawat bayi yang demam dan rewel akibat imunisasi. Ibu menjadi tidak khawatir dan tidak disalkahkan apabila anak demam dan rewel setelah imunisasi. Kebudayaan Aceh juga berlaku izin suami merupakan hal yang wajib bagi istri jika ingin melakukan suatau perbuatan termasuk imunisasi, sehingga apabilah suami mengizinkan ibu untuk mengimunisasi anak maka ibu bersemangat untuk melakukan imunisasi secara lengkap. Namun dari hasil penelitian ada beberapa Ibu ibu yang tidak mendapatkan dukungan dari keluarga namun tetap mengimunisasi anaknya dengan lengkap, hal ini karena ibu ibu sangat perduli terhadap kesehatan anaknya dan ibu ibu sangat mengetahui pentingnya imunisasi bagi anak.

e. Pengaruh Jarak rumah terhadap kelengkapan imunisasi dasar

Hasil penelitian penunjukkan bahwa Ibu dengan jarak rumah yang jauh dari tempat pelayanan kesehatan ada $50 \%$ dengan ststus imunisasi yang lengkap dan $60 \%$ dengan status imunisasi yang tidak lengkap. Hasil analisis bivariat didapatkan nilai $\mathrm{p} 0,50$ yang 
artinya tidak ada pengaruh antara jarak rumah Ibu dengan kelengkapan status imunisasi pada bayi.

Hasil penelitian ini sama dengan penelitian yang dilakukan oleh Prayogo, dkk (2009) menyatakan tidak adanaya hubungan jarak tempat pelayanan imunisasi dengan kelengkapan imunisasi pada anak. Kecenderungan orangtua yang memiliki rumah dengan jarak yang lebih dekat ke tempat pelayanan imunisasi memiliki anak dengan imunisasi yang lengkap. Selain jarak, kemudahan transportasi menuju ke tempat pelayanan imunisasi juga berpengaruh. Walaupun jarak dari tempat tinggal ke tempat pelayanan imunisasi jauh, tetapi jika mudah dijangkau maka imunisasi tetap dapat dilakukan.

Hasil penelitian yang berbeda dilakukan oleh Widyastuti, dkk (2008), ada hubungan jarak rumah dengan perilaku ibu mengimunisasi bayinya. Hal ini dikarenakan jarak rumah yang dekat akan memudahkan para ibu memanfaatkan pelayanan imunisasi yang optimal. Sebaliknya dengan jarak rumah yang jauh dari tempat pelayanan imunisasi menyebabkan para ibu enggan untuk mengimunisasi bayinya.

Menurut Maryati (2010) dalam Astini (2014), jarak tempuh penerima pelayanan menjadi salah satu pertimbangan untuk mencari fasilitas pelayanan kesehatan karena selain melibatkan waktu tempuh ke fasilitas tersebut juga melibatkan transportasi dan biaya yang dibutuhkan. Pertimbangan tersebut akan menjadi sangat dioerhitungkan apabila tempat pelayanan kesehatan yang ada berada sangat jauh dari akses pelayanan kesehatan dengan tingkat perekonomian penduduk yang rendah.

Menurut peneliti jarak rumah mempengaruhi keluarga membawa anakanya untuk diimunisasi tetapi apabila jarak rumah yang jauh namun jalan yang dilalui tidak sulit atau aspal yang bagus maka ini tidak menjadi penghalang dengan jarak yang jauh tersebut. Namun dengan jarak yang dekat tetapi keluarga tetap tidak mengimunisasi anaknya karena alasan lainnya seperti vaksin palsu, takut anaknya akan demam tinggi hingga step, tidak diizinkan oleh suami dan isu yang beredar bahwa vaksin imunisasi mengandung enzim babi yang haram bagi umat Islam. Hal inilah yang sangat mencemaskan, ibu yang tinggal dekat dengan puskesmas dan tidak jauh dari tempat diselenggarakannya posyandu malah tidak mengimunisasi anaknya.

Hasil penelitian juga didapatkan ibu yang tinggalnya jauh dari puskesmas dan posyandu malah lengkap mengimunisasi bayinya hal ini disebkan karena pengetahuan Ibu 
yang tinggi tentang imunisasi, pendidikan Ibu juga sarjana dan sangat didukung oleh keluarganya.

\section{KESIMPULAN}

Berdasarkan hasil penelitian didapatkan ada pengaruh antara sikap petugas kesehatan dan dukungan keluarga terhadap kelengkapan imunisasi dasar karena nilai $\mathrm{p}<0.05$, sedangkan pengetahuan ibu, jumlah anak dan jarak rumah tidak memiliki pengaruh terhadap kelengkapan imunisasi dasar pada bayi karena nilai $\mathrm{p}>0.05$. Varibel yang paling dominan mempengaruhi kelengkapan imunisasi dasar pada bayi adalah dukungan kelurga (OR 12,73).

\section{SARAN}

Petugas kesehatan agar dapat memberikan pelayanan kesehatan yang optimal, professional dan ramah agar meningkatkan angka kelengkapan imunisasi dasar bayi di wilayah kerja Puskesmas Peukan Bada serta melakukan konseling dan penyuluhan untuk keluarga yang memiliki bayi tentang tujuan, manfaat dan jadwal imunisasi dasar pada anak.

\section{DAFTAR PUSTAKA}

Afriani, T. Andrajati, R. Supardi, S. 2014. Faktor Faktor Yang Berhubungan Dengan Kelengkapan Imunisasi Dasar Pada Anak dan Pengelolaan Vaksin Di Puskesmas dan Posyandu Kecamatan X Kota Depok. Naksah publikasi Buletin Penelitian Sistem Kesehatan Vol. 17 No. 2 April 2014.

Aziz, A. 2009. Pengantar ilmu keperawatan anak. Jakarta: Salemba Medika.

Dewi, Atika Putri. 2013. Hubungan tingkat pengetahuan ibu dengan pemberian imunisasi dasar lengkap pada bayi di kelurahan Parupuk Tabing wilayah kerja Puskesmas Lubuk buaya kota Padang. Jurnal kesehatan andalas vol 3 no 2 Tahun 2014 ISSN 2301-7406

Ilham. 2017. Hubungan dukungan keluarga dengan kepatuhan ibu melaksanakan imunisasi dasar lengkap pada bayi di wilayah kerja puskesmas Pemangkat Kabupaten Sambas. Naskah publikasi Universitas Tanjungpura

Ismet, Fitriyanti. 2013. Analisis Faktor-Faktor yang Berhubungan dengan Imunisasi Dasar Lengkap Pada Balita di Desa Botubarani Kecamatan Kabila Bone Kabupaten Bone Bolango. Skripsi Universitas Negeri Gorontalo

Kemenkes RI. 2016. Riset Kesehatan Dasar. Jakarta : Badan Penelitian dan pengembangan Kesehatan Kementerian kesehatan RI 
Notoatmodjo, S. 2012. promosi kesehatan dan prilaku kesehatan. Jakarta: rineka cipta.

Pamungkas, Rica Novi. 2016. Hubungan Jumlah Anak dalam Keluarga dengan Kelengkapan Imunisasi Dasar Anak Di Desa Sukowiryo Kecamatan Jelbuk Kabupaten Jember. Digital Repository Skripsi Universitas Jember.

Prayogo, Ari, dkk. 2009. Kelengkapan imunisasi dasar pada anak usia 1-5 tahun Jakarta Timur. Jurnal Sari Pediatri Vol 11 no.1 Juni.

Rahmawati, Adzaniyah I dan Umbul Chatarina. 2014. Faktor yang mempengaruhi kelengkapan imunisasi dasar di Kelurahan Krembangan Utara. Jurnal berkala epidemiologi vol 2 no 1 januari 2014

Rini, Anif Prasetyo. 2010. Hubungan antara Karakteristik, Jumlah Anak dan Pengetahuan Ibu terhadap Status Imunisasi dasar pada bayi di kelurahan Wonokusumo Kecamatan Semampir SurabayaThesis Universitas Airlangga.

Suparmanto. 2011. Hubungan Pengetahuan Kesehatan dengan Perilaku Sehat oleh Ibu-ibu Rumah tangga Di Kabupaten Malang dan PamekasanJakarta.

Utami, Rifmi, dkk. 2015. Hubungan dukungan keluarga dengan motivasi ibu dalam mendapatkan imunisasi dasar lengkap pada bayi usia 0-12 bulan di desa Nyabakan. Jurnal Kesehatan Wirajaya medika

Widiatuti, dkk. 2008. Analisis Faktor yang berhubungan dengan perilaku ibu dalam memberikan imunisasi dasar kepada bayinya di desa banyutowo Kabupaten Kendal. Jurnal Ilmu Kesehatan Universitas Muhammdiyah Semarang Vol1 no.1 ISSN 20850301 